\title{
Clinical and laboratory evaluation of patients afflicted with allergic asthma under immunotherapy
}

Falah Hasan Hade

Al Zahraa Consultant Centre for asthma and allergy Baghdad, Iraq

\begin{abstract}
:
Background: Allergy may be defined as a constellation of signs and symptoms in which the altered immunologic reaction between foreign substance (allergens) and antibodies resulting in pathologic reactions referred as allergic reactions.
\end{abstract}

Allergic asthma is well known type 1- allergic reaction Up to $30 \%$ of general population suffers from various form of this malady during normal life span.

Objectives: To evaluate the effects of immunotherapy on groups of Iraqi patients afflicted with allergic asthma through some clinical and laboratories tests

Methods: A cross sectional study was carried out on Iraqi patients (males and females) in AL-Zahraa Consultant Center for Allergy and Asthma in Baghdad - Karkh, between Nov. 2005 - Apr. 2006 .The study included 60 asthmatic patients with ages between 6 and 45 years old who had allergy to house mites antigens "through skin test",A subcutaneous immunotherapy was given for 3 months, starting from diluted doses which were increased gradually. Clinical assessment was done depending on scoring of signs and symptoms, in addition to the medical history, clinical investigation, skin test, and pulmonary function test.

Results: Study showed that allergic asthma still affected all age group but tend to be higher in age group 31-45 years with male to female ratio $2: 1$. Of the sample investigated, $66.7 \%$ had positive skin reaction to House Mites which includes D1, D2 and D1+D2. The dust found to be one of main aggravating factors.Medical condition had shown significant improvement after three months of giving immunotherapy.

Conclusion: Immune therapy need to be considered as one of alternative treatment of allergic asthma decreasing the side effects and cost of different drugs used by these patients when given regularly to them.

Keywords: Asthma; immunotherapy; allergy

Received: July 29, 2019 Accepted: August 21, 2019 Published: September 9, 2019

\section{Introduction}

Allergic asthma is one of the diseases of type 1 hyper sensitivity reaction occur when IgE mast cell eosinophil mechanism is directed against a harmless antigen stimulus such as house mites, molds, pollens, insects and animal protein, subsequent exposure of the host to specific antigen allow for cross linking of mast cell bound $\operatorname{IgE}$ lead to mast cell activation and degranulation with rapid release of potent vasoactive and powerful mediators of inflammation which lead to smooth muscle contraction, tissue inflammatory cells re-

This is an open-access article distributed under the terms of the Creative Commons Attribution Non-Commercial License

(http://creativecommons.org/licenses/by-nc/4.0/), which permits non-commercial use, distribution, and reproduction in any medium, provided the original work is properly cited. 
lease, vasodilation,increase capillary permeability, glandular hypersecretion, leading to dyspnea, wheezing, cough, and sneezing.

The present study was aimed to assess the clinical and laboratory outcomes of certain groups of patients having allergic asthma after administering immunotherapy.

\section{Methods}

This study was carried out on Iraqi patients (male and female) attending at AL-Zahra consultant center for Allergy and Asthma in Baghdad from period between November2005 and April 2006.

The prospective study was carried on sixty patients afflicted with allergic asthma with age group ranged between 6 and 45 years who had allergy to house mites antigens only through skin tests done to them.

All patients evaluate before and after three months of giving immunotherapy which based on medical history, physical examination, in addition to skin test, pulmonary function test.

Immunotherapy giving to them, starting with low concentration $\quad(0.2 \mathrm{ml} / 100000 \quad$ IC $)$ increases concentration gradually every week till reaches $(0.1 \mathrm{ml} / 1000 \mathrm{IC})$ giving by subcutaneous injection. Skin test was done to all patients and at first presentation and three months after giving immunotherapy according to skin test protocol, which carried out by skin prick method for all allergens except Dermatophogoidespteronyssinus (D1) and Dermatophogoidesfarinae (D2) which were giving by intradermal method. Fifteen types of allergens extract used in skin test including moulds, pollens, grasses, and mites(D1 and D2).

Pulmonary function test (P.F.T) were done to all patients before and after three months of giving immunotherapy through demonstration reversible airway obstruction which based on a reduction in FEV1 or in the ratio of FEV1 to FVC.

The assessment of clinical severity was conducted and based on (American thoracic society standardization of spirometry 1995). A questionnaire containing personal details with type and duration of disease, had been adopted for each patient. The clinical evaluation was based on the medication score and clinical signs and symptoms score.

The medication score range from:

Stage $0=$ patient needs medication, as the same before starting IT (same dose and same drug used ).

Stage 1 = patient had no need for any medication or decrease medication dose taken before giving IT.

Stage 2 = patient had an increased need for medication either increase in dose or addition of other medication after 3 months of giving IT.

Clinical signs and symptoms in are based on cough, dyspnea, wheezing, and sputum.

The degree of severity of these signs and symptoms were based on score which ranged from:

Stage $1=$ There was an improvement in signs and symptoms after 3 months of giving IT but not mean absolute absence of these signs and symptoms.

Stage 2 = Worsening and deterioration in the severity of these signs and symptoms after 3 months of IT. The summation of these 2 parameters (medications and symptoms scores).

Same: Which represent stage 0

Improve: Which represent stage 1

Worse: Which represent stage 2

\section{Statistical Analysis}

All the statistical analyses were done by using SPSS program (version-10) and Excel application. The categorical variables were expressed as numbers and 0.05 was chosen to be the cutoff level of significance.

\section{Results}

The study had shown that the majority of patients were in the age range group 31- 45 years, (50\%) with male to female ratio $2: 1$, also family history show major risk factor (65\%). From 200 patients (40\%) had positive skin reaction to mites antigen (D1,D2). Dust was shown as one of most aggravating factors (36.7\%). Skin reaction after three months of immunotherapy had shown decrease in severity with significant difference.

After three months of IT, (90\%) of patients showed improvement in their medical condition depending on medication score, clinical signs and symptoms. as shown in Table 1: 


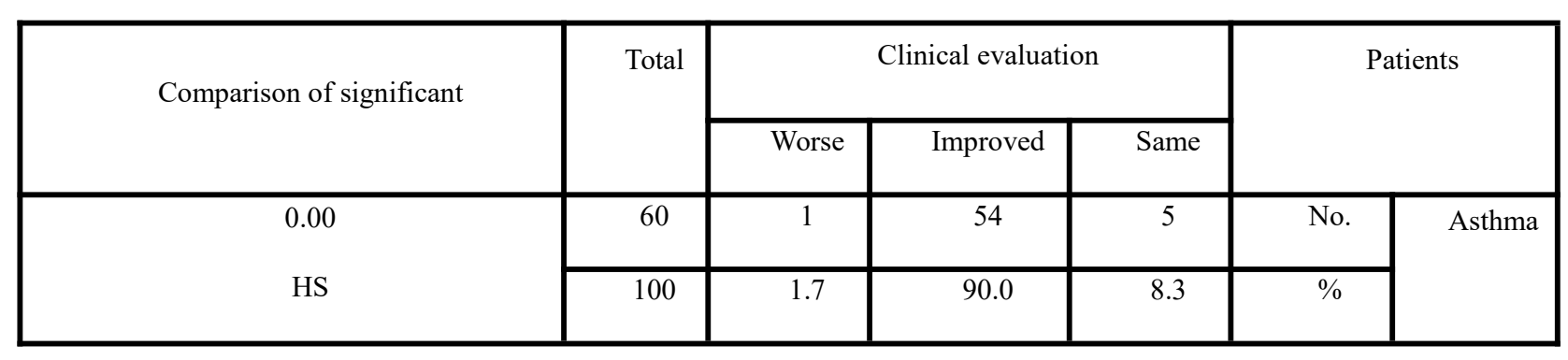

Table 1. Response of patients to immunotherapy

\section{Discussion}

From this study allergic asthma was still affected all age groups but tend to be higher in age group (31-45) years, and this agree to some extent with other studies which mentioned that this disease follows bimodal distribution, one at early age(4-10 years) and second after 40 years,with male afflicted more than female, which may be due to hormonal difference.

House mites (D1 and D2) had shown higher sensitization than other allergens, which may be probably due to heavy infestation of house mites in our country where hot and humid climate provides ideal habitat for mites growth and this agree with other study made on Iraqi patients,also dust had shown as one of main aggravating factors than other and this is due to nature of climate and geographic area of our country.The severity of skin reaction to mites antigen had shown some change toward mild form after three months of IT, and this may be most probably due to the effect of IT on immunological state of patients through variety of immunological modification including the production of IgG blocking antibody, lowering of specific IgE antibodies, decrease sensitivity of basophile and mast cell to antigen including histamine release and modulation of $\mathrm{T}$ cell response, reduce in mast cell numbers, with consequent reduction in immediate allergic sensitivity.

The improvement of clinical conditions after three months of giving IT to patients (90\%) employed in this studies depending on parameters mentioned previously are compatible with many previous studies done by Coltage, Majori, Bousguent and our results disagreed with Choovoravech, these difference may be related to difference in the duration of IT, the route of administration of vaccine, severity and duration of disease, age groups, also difference in the environmental condition that surround the studied group.

\section{Conclusion and recommendation}

Immune therapy need to be considered as one of alternative treatment of allergic asthma decreasing the side effects and cost of different drugs used by these patients when given regularly to them.

Aerobiological studies are needed for detection of prevalent allergens in atmosphere and their concentration with detection of their seasonal distribution in different parts of our country, with further improvement in specific IT by more accurate purification and standardization of allergen extracts.

\section{References}

1. Kaliner $\mathrm{M}$ and Lamaske R. Rhinitis and asthma JAMA 1992; 268: 2807-2829.

2. Abba I and Terr MD. The atopic diseases: In: Medical immunology. (10 thed). MacGraw Hill, publishing division; 2001. p. 344-364.

3. Togias A. Unique mechanistic features of allergic rhinitis. J. Allerg. Clin. Immunol. 2000; (105): S599-S604.

4. Platts $\mathrm{N}$ and Mills T. Hypersensitivity Type 1. In: Immunology, $\left({ }^{6 \text { th }}\right.$ ed). Mosby; 2002.

5. Pepys J. Skin test in diagnosis. In: Clinical aspects of immunology ( $\left.3^{\text {rd }} \mathrm{ed}\right)$. Oxford: Black Well Scientific Publication; 1975. p. 55-80. Cited by Burrows B, Martines F, Halonen $\mathrm{M}$, et al. Association of asthma with serum IgE levels and skin test reactivity to allergen, N. Engl. J. Med., 1989; (320): 271-277. Spain. p. 324-341.

6. Enright PL, Lebowitz MD, Cockroft DW. Physiologic measure: Pulmonary function test, Asthma outcome. Am. J. Respir. Crit. Care. Med; 1994; (149): 459-518.

7. National Heart, Lung, and blood Institute National Asthma Education and Prevention program (NAEPP), Exper. Panel Report 2: Guidelines for the diagnosis and management of asthma: National Institutes of Health, USA Pub. No: 97-4051. 1999.

8. Sorlie DE. Medical biostatistics \& epidemiology: 
Examination \& board review. First ed. Norwalk, Connecticut, Appleton \& Lange 1995. p. 47-88.

9. Rotheriberg M E. Eosinophilia. Eng.I. Med; 1998; (338): 1592-1600.

10. Duffy DL. Applying statistical approaches in the dissection of genes versus environment for asthma and allergic disease. Curr.Opin. 2001.

11. Ono SJ. Molecular genetics of allergic diseases. Ann. Rev. Immunol. 2000; (18): 347-366.

12. A-AL-Taie M. Immunological study on allergic assessment of asthmatic patients. College of Science, AL-Mustansiriya University. Iraq. (Ph. D.Thesis). 2002.

13. Boulet LP, Tarcotte H, Laprise C, et al. Comparative degree and type of sensitization to common indoor and outdoor. 1997.

14. Herbert FA, Weimer N, Salkie ML. RAST and skin test screening in the investigation of asthma. Ann. Allergy 1982; (49): 6-12.

15. Durham Sr, Varney VA, Gaga M, et al. (1999): Grass pollen immunotherapy decreases the number of mast cells in the skin. Clinical and Experimental Allergy 1999; (29): 1490.

16. Fischer TJ, O'Brien KP, Entis GN. Basic principles of therpy for allergic diseases In: Manual of allergy and Immunology. ( $3^{\text {rd }}$ ed). USA. Ch 4; 1995. p. 51-93.

17. Majori M, Caminati A, Corradi M, Brianti E, Scarpa S, Pesci A. T-cell cytokine pattern at three time points during specific immunotherapy for mite-sensitive asthma . Clin Exp Allergy 2000; (30): 341-7.

18. Bousquet J, Hejjaoui A, Clauzel AM, et al. Immunotherapy with a standard Dermatophogoidespteronyssinusextract.II.

Prediction of efficacy of immunotherapy. Allergy; 1988; (30): 190-195.

19. Ko-Huang L, Yung-Hsiang L, Hai-Lun S, Ko-Hsiulu J, Cheng H, Ming-Chin. Clinical and immunological effects of sublingual immunotherapy in asthmatic children sensitized to mites: a double - blind, randomized, placebo-controlled study. Pediatric Allergy and Immunology 2006; (17): 408.

20. Choovoravech P. (1974): Effects of immunotherapy in bronchial asthma; treatment with extracts of house dust and mite. Med. Assoc. Thai 1974; (57): 445-449. 